\title{
A Double-Sided View to Adult Vaccination: The Opinions and Attitudes of Patients and Health Workers
}

\author{
Raziye Şule Gümüştakım¹, Pınar Bilgili1, Murat Çevik1, Duygu Ayhan Başer2, Adem Doğaner1, \\ Selda Handan Karahan Saper ${ }^{1}$, Zuhal Kanevetci ${ }^{1}$, Ergül Özçelebi ${ }^{1}$ \\ ${ }^{1}$ Medical Faculty, Sütcü Imam University, Kahramanmaraş, Turkey \\ ${ }^{2}$ Department of Family Medicine, Medical School, Hacettepe University, Ankara, Turkey \\ Email: sulesu82@mynet.com, drpinarbilgili@gmail.com, muratcevik1707@gmail.com, ^duyguayhan@outlook.com, \\ adem_doganer@hotmail.com,drhandankarahan@hotmail.com,zuhalkanevetci@yahoo.com,ergulozcelebi@gmail.com
}

How to cite this paper: Gümüştakım, R.Ş., Bilgili, P., Çevik, M., Ayhan Başer, D., Doğaner, A., Karahan Saper, S.H., Kanevetci, Z. and Özçelebi, E. (2018) A Double-Sided View to Adult Vaccination: The Opinions and Attitudes of Patients and Health Workers. Health, 10, 1697-1713.

https://doi.org/10.4236/health.2018.1012128

Received: September 12, 2018

Accepted: December 10, 2018

Published: December 13, 2018

Copyright $(9) 2018$ by authors and Scientific Research Publishing Inc. This work is licensed under the Creative Commons Attribution International License (CC BY 4.0).

http://creativecommons.org/licenses/by/4.0/

\begin{abstract}
Objective: Although there are adult vaccination schemes in our country, there are serious deficiencies in the way that doctors direct the patients to this vaccination, but also patients have to make and demand these vaccinations. The aim of our study is to identify the shortcomings in this area and draw a roadmap for what arrangements should be made in terms of physicians and patients in order to increase adult immunization rates in primary care. Method: We conducted a two-phase, multicentered, descriptive clinical trial between October and December 2017. The first phase of the trial was carried out with patients from 3 Family Health Centers in Antalya, Istanbul and Osmaniye. Patients to be interviewed were selected voluntarily among Family Health Center's applicants. The second phase of the trial was carried out with health workers, who were participated to trial from 26 different provinces of Turkey. In the process, a questionnaire of 19 questions was applied to primary health care workers by the internet. Results: 490 patients were included in the study. There was a significant difference between gender, age, education level and guideline follow-up and vaccination status of patients [ $p<0.05]$. 794 primary health care workers participated in the survey. There was a statistically significant difference between gender, age groups, education and follow-up of guidelines and vaccination status [p $<0.05]$. Conclusion: As a result of the studies including our study about adult vaccination, only $10 \%$ $20 \%$ of the targeted groups in adults can be vaccinated. However, just like in childhood during adulthood, vaccinations protect individuals from diseases and provide economic benefits. Firstly, the knowledge level of physicians on adult immunization should be updated with in-service trainings, they should
\end{abstract}


first be convinced to vaccinate because they are in risk group and then they should be recommended vaccination to patient to increase the vaccination rates.

\section{Keywords}

Adult Vaccination, Health Workers, Patients

\section{Introduction}

One of the most effective and safe preventive health services in preventing communicable diseases and protecting against infectious diseases is being vaccinated. In countries with high vaccination rates under the Extended Immunization Program [EIP], the incidence and mortality of vaccine-preventable diseases have been reduced and these diseases have been brought to the elimination point [1].

Although adulthood is considered as the most healthy life period, infectious diseases are less common in this age group than other age groups. In addition, continuation of immunization services during the adult and elderly periods is very important due to the fact that some vaccine protections in childhood do not last for a lifetime, susceptibility to vaccine-preventable diseases increases when cannot be vaccinated during childhood and people stay face to face with vaccine-preventable diseases in working and social environments.

A study conducted in adults aged 18 years and over in our country reported that $65 \%$ of the participants in the study had diphtheria, $69 \%$ had tetanus, $90 \%$ had pertussis seronegativity and $78 \%$ of the participants need tetanus vaccination, $90 \%$ need pertussis vaccination and $96 \%$ need diphtheria vaccination [1]. Another study conducted in our country in 2017 showed that $32.5 \%$ of tetanus patients who were hospitalized were died and $17 \%$ of the survivors developed sequelae [2]. This number is predicted to decrease as adult vaccination rates increase.

However preparations and accessibility to vaccination in adulthood period are not enough as childhood period. In recent years adult vaccination has attracted more attention.

Adults have a number of vaccines recommended in relation to age, previous vaccination status, current health status, lifestyle, working conditions, immunosuppressive drugs and treatments and travel [3] [4] [5] [6]. Vaccination recommendations and doses in adults according to 2016 adult immunization Schedule are shown in Table 1.

Within the scope of the Adult Vaccination Program in our country, social mobilization activities have been planned with the slogan of "Come on adults to vaccination" and it is aimed to increase the applications of the people in the target group to make necessary vaccinations for health institutions and organizations. In this context, influenza vaccinations are paid each year and pneumococcal 
Table 1. Vaccination recommendations and doses in adults.

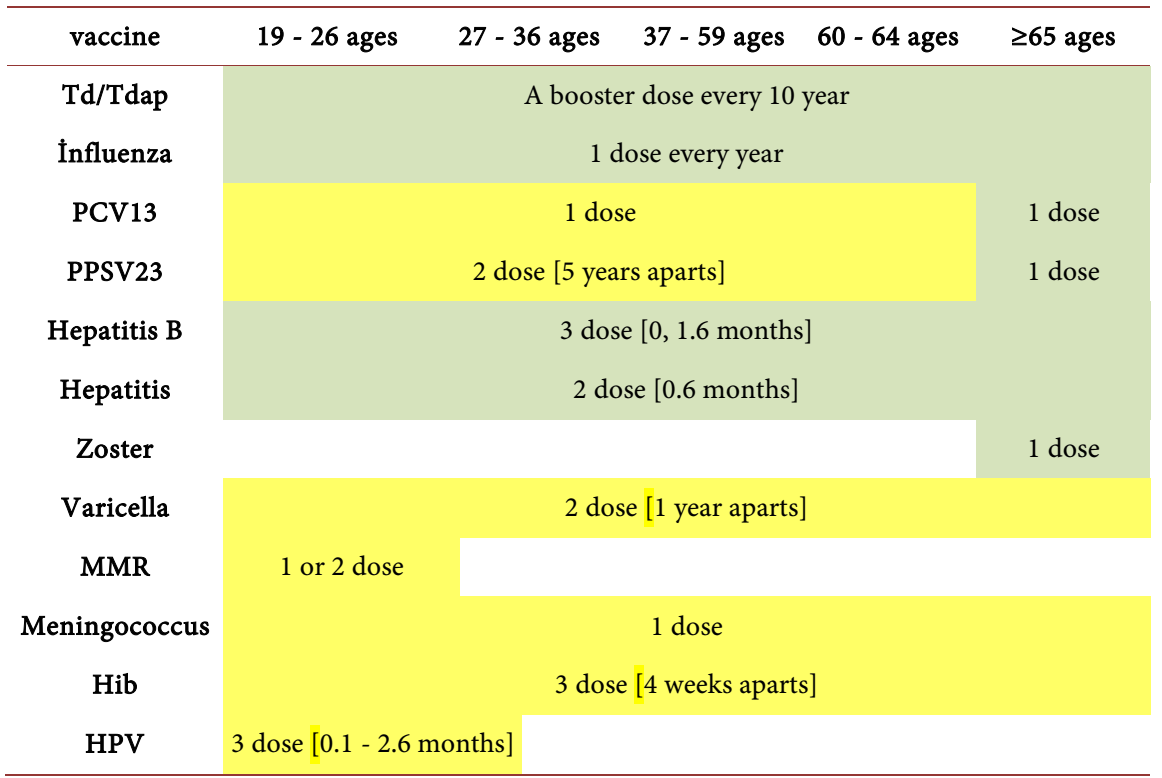

Td: Tetanus-diphtheria; Tdap: Tetanus-diphtheria-acellular pertussis; Hib: Haemophilus influenzae type b vaccine; HPV: Human papilloma virus vaccine; KKK: measles-rubella-mumps vaccine; PCV13: Conjugated pneumococcal vaccine; PPSV23: Polysaccharide pneumococcal vaccine. $\square$ Application to all adults is recommended. $\square$ It is advisable to apply to adults with a risk factor or indication. $\square$ It is not a special proposal but can be applied at the request of the patient and the physician.

vaccinations are paid every five years in order to have a medical report documenting these cases of high-risk people [7].

Although there are adult vaccination schemes in our country, there are serious deficiencies in the way that doctors direct the patients to this vaccination, but also patients have to make and demand these vaccinations.

The aim of our study is to identify the shortcomings in this area and draw a roadmap for what arrangements should be made in terms of physicians and patients in order to increase adult immunization rates in primary care.

\section{Material-Method}

We conducted a two-phase, multicentered, descriptive clinical trial between October and December 2017.

The first phase of the trial was carried out with patients from 3 Family Health Centers in Antalya, Istanbul and Osmaniye. The sample selected did not represent the whole population. Patients to be interviewed were selected voluntarily among Family Health Center's applicants. Survey was conducted by researchers using face-to-face interview techniques. A questionnaire contained demographic information of patients and 22 questions prepared for assessing the information, attitudes and behaviors of the patients about the adult periodic vaccinations.

The second phase of the trial was carried out with health workers, who were participated to trial from 26 different provinces of Turkey. The sample selected represents the whole population. In the process, a questionnaire of 19 questions was applied to primary health care workers by the internet. The questions con- 
sist of sociodemographic characteristics of primary health care workers and their thoughts about adult immunization.

The survey was conducted in accordance with the Helsinki Declaration criteria. Prior to the trial, the etical approval was taken from Clinical Investigations Ethics Committee of Faculty of Medicine of Kahramanmaraş Sütçü İmam University [ethics committee 2017/14 decision no: 11]. As a result of our research, the obtained data has been transferred to the computer environment.

\section{Statistical Analysis}

In the statistical evaluation of intermittent data, Kikare analysis and Exact test were used. Ratios and frequencies are used as statistical parameters. Statistical significance was accepted as $\mathrm{p}<0.05$. Statistical evaluation of the data was performed using the IBM SPSS 22 [IBM SPSS for Windows version 22, IBM Corparation, Armonk, New York, United States] package program.

\section{Results}

\subsection{The First Phase}

490 patients were included in the study and $62.9 \%$ of the patients were female; $74.4 \%$ are in the age group of 50 years and over. $64.7 \%$ are married, $41 \%$ are primary school graduates and the income level of $74.2 \%$ is between $0-1999 \mathrm{TL}$. All of the patients were living in urban areas and $94.9 \%$ of them have general health insurance and $43.5 \%$ are housewives. Knowledge levels of the patients about adult inoculation and chronic disease states are shown in Table 2.

When the sociodemographic characteristics of the patients were compared with their attitudes about adult vaccination, statistical difference was found between having knowledge about vaccination and education level $[\mathrm{p}=0.001]$ and occupation $[\mathrm{p}=0.046]$. There was a statistically significant difference only between information-acquired vaccine and education level $[p=0.001]$. The sociodemographic characteristics and vaccination relationship showed in Table 3.

There was a significant difference between thinking that adult vaccination was beneficial and gender and educational level, and women and primary school graduates were believe more in the benefit of vaccination [ $p<0.05]$.

Table 2. Knowledge levels of patients about adult vaccination.

\begin{tabular}{cccc}
\hline & & $\mathrm{n}$ & $\%$ \\
\hline Do you have any chronic diseases? & Yes & 384 & 78.4 \\
If you have any chronic illness & No & 106 & 21.6 \\
[you can select more than one option]? & Other Diseases & 76 & 19.8 \\
& Diabetes [Diabetes] & 42 & 10.9 \\
Do you have any information & Hypertension & 242 & 63.0 \\
about adult vaccinations? & Heart Disease & 24 & 6.3 \\
& Yes & 416 & 84.9 \\
\hline
\end{tabular}




\section{Continued}

\begin{tabular}{|c|c|c|c|}
\hline \multirow{6}{*}{$\begin{array}{l}\text { Which vaccinations do you } \\
\text { have information about? }\end{array}$} & Other & 3 & 0.6 \\
\hline & None & 49 & 10.0 \\
\hline & Influenza [girp] & 420 & 85.7 \\
\hline & Rabies & 8 & 1.6 \\
\hline & Pneumococcus [pneumonia] & 2 & 0.4 \\
\hline & Tetanus & 8 & 1.6 \\
\hline \multirow[t]{7}{*}{ Where would you like to receive information? } & Family Medicine physicians & 421 & 85.9 \\
\hline & $\begin{array}{c}\text { Does Not Want to take informa- } \\
\text { tion }\end{array}$ & 15 & 3.1 \\
\hline & Brochures & 3 & 0.6 \\
\hline & Other Physicians & 17 & 3.5 \\
\hline & Pharmacy & 1 & 0.2 \\
\hline & Internet & 4 & 0.8 \\
\hline & Public Spots & 29 & 5.9 \\
\hline \multirow{3}{*}{$\begin{array}{l}\text { Did you get vaccinated } \\
\text { during the adult period? }\end{array}$} & Yes & 294 & 60.0 \\
\hline & I do not remember & 10 & 2.0 \\
\hline & No & 186 & 38.0 \\
\hline \multirow[t]{5}{*}{ Which vaccinations have you done? } & Other & 10 & 2.0 \\
\hline & None & 189 & 38.6 \\
\hline & Influenza [influenza] & 205 & 41.8 \\
\hline & Pneumococcus [pneumonia] & 19 & 3.9 \\
\hline & Tetanus & 67 & 13.7 \\
\hline \multirow{4}{*}{$\begin{array}{c}\text { If not, why? } \\
\text { [You can select more than one option.] }\end{array}$} & Other & 50 & 21.2 \\
\hline & Not knowledge about vaccination & 81 & 34.3 \\
\hline & Fear of vaccination & 60 & 25.4 \\
\hline & $\begin{array}{l}\text { Not believing in the efficacy of } \\
\text { vaccination }\end{array}$ & 45 & 19.1 \\
\hline \multirow[t]{3}{*}{ Are adult vaccines beneficial for you? } & Yes & 353 & 72.0 \\
\hline & No idea & 125 & 25.5 \\
\hline & No & 12 & 2.4 \\
\hline \multirow{4}{*}{$\begin{array}{l}\text { If you think it is useful, } \\
\text { who do you think should be vaccinated? }\end{array}$} & Other & 40 & 10.3 \\
\hline & To be bitten by an animal & 77 & 19.8 \\
\hline & pregnant & 76 & 19.6 \\
\hline & People with chronic illness & 195 & 50.3 \\
\hline \multirow{4}{*}{$\begin{array}{l}\text { Which diseases can be } \\
\text { prevented by adult vaccination? }\end{array}$} & Other & 11 & 2.8 \\
\hline & Influenza [influenza] & 137 & 35.2 \\
\hline & Rabies & 111 & 28.5 \\
\hline & Pneumonia [pneumonia] & 130 & 33.4 \\
\hline
\end{tabular}


Table 3. Sociodemographic characteristics-Vaccination relationship.

\begin{tabular}{|c|c|c|c|c|c|c|c|c|c|c|c|c|}
\hline & & \multicolumn{10}{|c|}{ Which vaccinations have you done? } & \multirow[b]{3}{*}{$\mathrm{p}$} \\
\hline & & \multicolumn{2}{|c|}{ None } & \multicolumn{2}{|c|}{ Influenza } & \multicolumn{2}{|c|}{$\begin{array}{l}\text { Pneumo- } \\
\text { coccus }\end{array}$} & \multicolumn{2}{|c|}{ Tetanus } & \multicolumn{2}{|c|}{ Other } & \\
\hline & & $\mathrm{n}$ & $\%$ & $\mathrm{n}$ & $\%$ & $\mathrm{n}$ & $\%$ & $\mathrm{n}$ & $\%$ & $\mathrm{n}$ & $\%$ & \\
\hline \multirow[t]{2}{*}{ Gender } & Male & 73 & 38.6 & 87 & 42.4 & 4 & 21.1 & 14 & 20.9 & 4 & 40.0 & $0.015^{*}$ \\
\hline & Female & 116 & 61.4 & 118 & 57.6 & 15 & 78.9 & 53 & 79.1 & 6 & 60.0 & \\
\hline \multirow[t]{4}{*}{ Age } & $18-29$ & 9 & 4.8 & 3 & 1.5 & 0 & 0.0 & 11 & 16.4 & 0 & 0.0 & $0.001^{*}$ \\
\hline & $30-39$ & 13 & 6.9 & 15 & 7.4 & 0 & 0.0 & 19 & 28.4 & 2 & 20.0 & \\
\hline & $40-49$ & 24 & 12.7 & 11 & 5.4 & 0 & 0.0 & 16 & 23.9 & 2 & 20.0 & \\
\hline & 50 and up & 143 & 75.7 & 175 & 85.8 & 19 & 100.0 & 21 & 31.3 & 6 & 60.0 & \\
\hline \multirow{5}{*}{$\begin{array}{c}\text { Marital } \\
\text { status }\end{array}$} & Living separate & 5 & 2.6 & 3 & 1.5 & 0 & 0.0 & 1 & 1.5 & 0 & 0.0 & 0.190 \\
\hline & Single & 17 & 9.0 & 14 & 6.8 & 0 & 0.0 & 10 & 14.9 & 0 & 0.0 & \\
\hline & Divorced & 10 & 5.3 & 10 & 4.9 & 0 & 0.0 & 3 & 4.5 & 1 & 10.0 & \\
\hline & Widow & 37 & 19.6 & 52 & 25.4 & 4 & 21.1 & 4 & 6.0 & 2 & 20.0 & \\
\hline & Married & 120 & 63.5 & 126 & 61.5 & 15 & 78.9 & 49 & 73.1 & 7 & 70.0 & \\
\hline \multirow[t]{6}{*}{ Education } & Primary school & 73 & 38.6 & 95 & 46.3 & 8 & 42.1 & 20 & 29.9 & 5 & 50.0 & $0.048^{*}$ \\
\hline & High school & 46 & 24.3 & 37 & 18.0 & 2 & 10.5 & 19 & 28.4 & 2 & 20.0 & \\
\hline & $\begin{array}{l}\text { No reading and } \\
\text { writing }\end{array}$ & 19 & 10.1 & 15 & 7.3 & 4 & 21.1 & 5 & 7.5 & 1 & 10.0 & \\
\hline & Middle School & 20 & 10.6 & 11 & 5.4 & 2 & 10.5 & 8 & 11.9 & 0 & 0.0 & \\
\hline & University & 18 & 9.5 & 36 & 17.6 & 0 & 0.0 & 13 & 19.4 & 2 & 20.0 & \\
\hline & College & 13 & 6.9 & 11 & 5.4 & 3 & 15.8 & 2 & 3.0 & 0 & 0.0 & \\
\hline \multirow[t]{2}{*}{ Residence } & Urban & 189 & 100.0 & 205 & 100.0 & 19 & 100.0 & 67 & 100.0 & 10 & 100.0 & - \\
\hline & Rural & 0 & 0.0 & 0 & 0.0 & 0 & 0.0 & 0 & 0.0 & 0 & 0.0 & \\
\hline \multirow[t]{6}{*}{ Occupation } & Not working & 7 & 3.7 & 7 & 3.4 & 0 & 0.0 & 2 & 3.0 & 0 & 0.0 & $0.001^{*}$ \\
\hline & Retired & 60 & 31.7 & 88 & 42.9 & 4 & 21.1 & 9 & 13.4 & 3 & 30.0 & \\
\hline & Housewife & 83 & 43.9 & 83 & 40.5 & 14 & 73.7 & 29 & 43.3 & 4 & 40.0 & \\
\hline & Worker & 34 & 18.0 & 18 & 8.8 & 1 & 5.3 & 20 & 29.9 & 3 & 30.0 & \\
\hline & Officer & 5 & 2.6 & 8 & 3.9 & 0 & 0.0 & 6 & 9.0 & 0 & 0.0 & \\
\hline & Student & 0 & 0.0 & 1 & 0.5 & 0 & 0.0 & 1 & 1.5 & 0 & 0.0 & \\
\hline \multirow{2}{*}{$\begin{array}{l}\text { Chronical } \\
\text { disease }\end{array}$} & Yes & 143 & 75.7 & 185 & 90.2 & 19 & 100.0 & 31 & 46.3 & 6 & 60.0 & $0.001^{*}$ \\
\hline & No & 46 & 24.3 & 20 & 9.8 & 0 & 0.0 & 36 & 53.7 & 4 & 40.0 & \\
\hline
\end{tabular}

Kikare test; Exact test; Frequency distributions of a: $0.05^{\star}$ groups were statistically significant.

When compared to the sociodemographic characteristics of patients with who should be vaccinated, sex, age, marital status, level of education, occupation and presence of chronic illness were found statistically significant $[p<0.001]$. Sociodemographic characteristics-thought about who should be vaccinated relationship showed in Table 4. 
Table 4. Sociodemographic characteristics-thought about who should be vaccinated relationship.

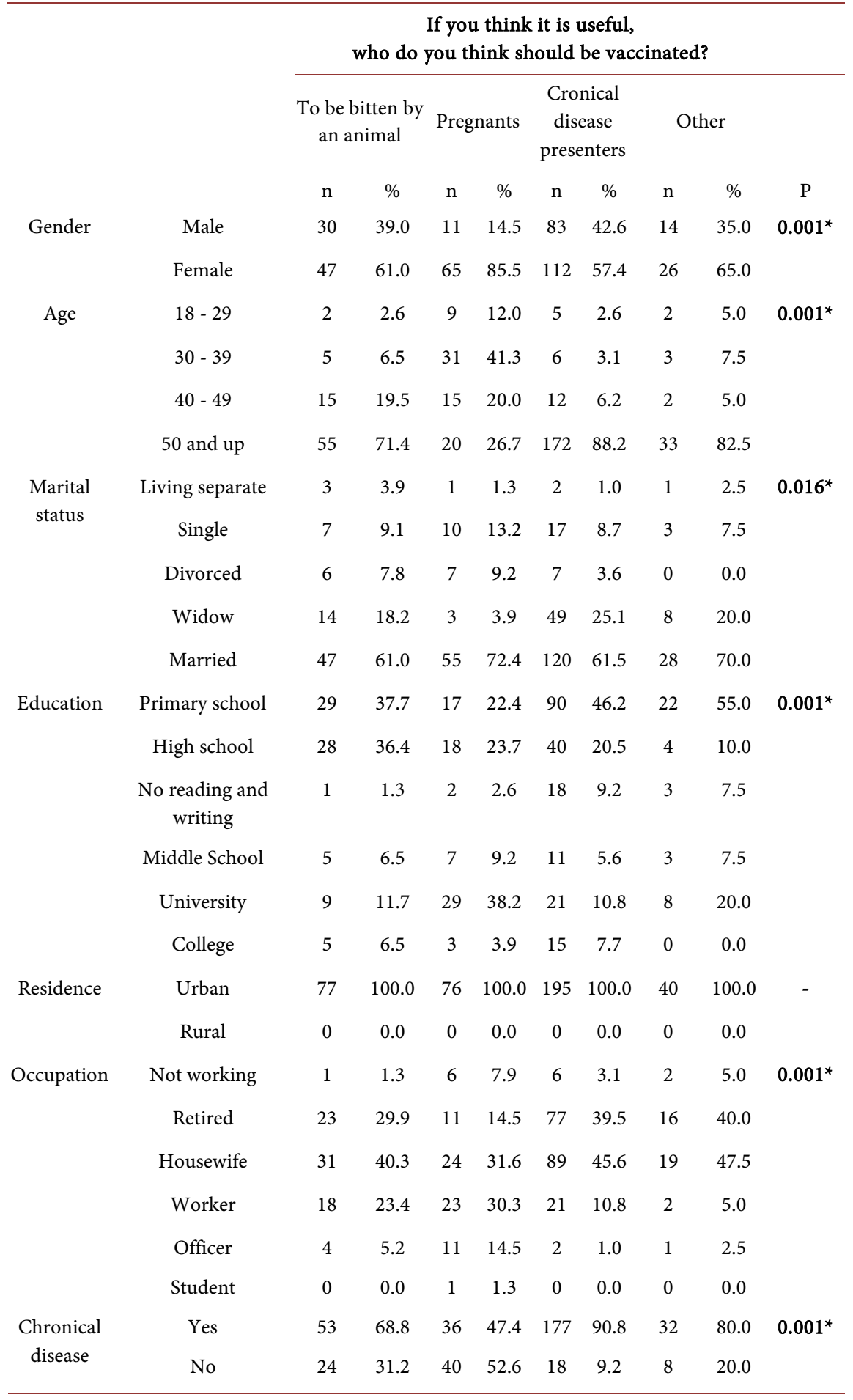

Kikare test; Exact test; Frequency distributions of a: $0.05^{\star}$ groups were statistically significant.

Statistically significant difference was found between the knowledge about the diseases prevented with adult vaccination and the level of education $[\mathrm{p}=0.001]$ and the presence of chronic illness $[p=0.01]$. The most of patients believe in- 
fluenza [35.2\%] and pneumococus [33.4\%] can be prevented with vaccination. The biggest part of primary school graduates believe that vaccination can prevent only influenza, while the biggest part of patients with chronic illnesses believe that pneumonia and influenza can be prevented by vaccination.

The relationship between vaccination and having information about vaccination showed in Table 5.

92.5\% of patients who have vaccinated during adulthood want to receive information from family medicine and $94.2 \%$ of them were vaccinated. These values were also statistically significant $[\mathrm{p}<0.001]$.

\subsection{The Second Phase}

794 primary health care workers participated in the survey and $82.5 \%$ [655] were female. $38.9 \%$ of the participants are in the age group of $25-34,38.1 \%$ are in the age group of 35 - $44.72 .4 \%$ are married, $52.4 \%$ are midwives and nurses, and $41 \%$ are family physicians. $79.8 \%$ of the participants are working in the urban area and $37.6 \%$ of them are studying since $0-9$ years. The health workers' attitudes towards adult vaccination are shown in Table 6.

A statistically significant difference was found between vaccination suggestion and education in this subject [ $\mathrm{p}=0.017] .51 \%$ of those recommending vaccination are midwives and nurses, while $42.6 \%$ are family practitioners, $48.9 \%$ of primary health care workers who those who are educated in this regard were suggesting vaccination.

There was a statistically significant difference between gender, age groups, education and follow-up of guidelines and vaccination status [ $p<0.05]$. In females,

Table 5. The relationship between vaccination and having information about vaccination.

\begin{tabular}{|c|c|c|c|c|c|c|c|c|}
\hline & & \multicolumn{6}{|c|}{$\begin{array}{l}\text { Did you get vaccinated during the } \\
\text { adult period? }\end{array}$} & \multirow[b]{3}{*}{$\mathrm{p}$} \\
\hline & & \multicolumn{2}{|c|}{ Yes } & \multicolumn{2}{|c|}{$\begin{array}{l}\text { Don't } \\
\text { remember }\end{array}$} & \multicolumn{2}{|c|}{ No } & \\
\hline & & $\mathrm{n}$ & $\%$ & $\mathrm{n}$ & $\%$ & $\mathrm{n}$ & $\%$ & \\
\hline \multirow[t]{7}{*}{$\begin{array}{c}\text { Where do you want to get } \\
\text { your information? }\end{array}$} & $\begin{array}{l}\text { Family Medicine } \\
\text { physicians }\end{array}$ & 272 & 92.5 & 7 & 70.0 & 142 & 76.3 & $0.001^{*}$ \\
\hline & $\begin{array}{l}\text { Does Not Want to } \\
\text { take information }\end{array}$ & 3 & 1.0 & 2 & 20.0 & 10 & 5.4 & \\
\hline & Brochures & 3 & 1.0 & 0 & 0.0 & 0 & 0.0 & \\
\hline & Other Physicians & 10 & 3.4 & 0 & 0.0 & 7 & 3.8 & \\
\hline & Pharmacy & 1 & 0.3 & 0 & 0.0 & 0 & 0.0 & \\
\hline & Internet & 0 & 0.0 & 0 & 0.0 & 4 & 2.2 & \\
\hline & Public Spots & 5 & 1.7 & 1 & 10.0 & 23 & 12.4 & \\
\hline \multirow{2}{*}{$\begin{array}{c}\text { Do you have any information } \\
\text { about adult vaccinations? }\end{array}$} & Yes & 277 & 94.2 & 7 & 70.0 & 132 & 71.0 & $0.001^{*}$ \\
\hline & No & 17 & 5.8 & 3 & 30.0 & 54 & 29.0 & \\
\hline
\end{tabular}

Kikare test; Exact test; Frequency distributions of a: $0.05^{\star}$ groups were statistically significant. 
Table 6. Health workers' attitudes towards adult vaccination.

\begin{tabular}{|c|c|c|c|}
\hline & & $\mathrm{n}$ & $\%$ \\
\hline \multirow{2}{*}{$\begin{array}{l}\text { Have you ever been trained } \\
\text { in adult vaccination before? }\end{array}$} & Yes & 380 & 47.9 \\
\hline & No & 414 & 52.1 \\
\hline \multirow{2}{*}{$\begin{array}{l}\text { If you did not receive training, } \\
\text { would you like to study in this subject? }\end{array}$} & Yes & 545 & 83.6 \\
\hline & No & 107 & 16.4 \\
\hline \multirow{2}{*}{$\begin{array}{l}\text { Do you follow the } \\
\text { guidelines on vaccination? }\end{array}$} & Yes & 643 & 81.0 \\
\hline & No & 151 & 19.0 \\
\hline \multirow{3}{*}{$\begin{array}{l}\text { Do you think you have enough } \\
\text { information about adult vaccination? }\end{array}$} & Yes & 273 & 34.4 \\
\hline & No & 211 & 26.6 \\
\hline & Undecided & 310 & 39.0 \\
\hline \multirow{4}{*}{$\begin{array}{l}\text { If yes to the previous question, } \\
\text { where did you get this information? }\end{array}$} & From vaccination guidelines & 253 & 71.7 \\
\hline & From educations & 72 & 20.4 \\
\hline & From social platforms & 16 & 4.5 \\
\hline & other & 12 & 3.4 \\
\hline \multirow{2}{*}{$\begin{array}{l}\text { Do your adult patients } \\
\text { recommend vaccination? }\end{array}$} & Yes & 751 & 94.6 \\
\hline & No & 43 & 5.4 \\
\hline \multirow{4}{*}{$\begin{array}{l}\text { If so, which patient } \\
\text { group do you recommend? }\end{array}$} & pregnant & 41 & 5.5 \\
\hline & People with chronic illness & 608 & 81.3 \\
\hline & Those with suspicious contact stories & 44 & 5.9 \\
\hline & other & 55 & 7.4 \\
\hline \multirow{6}{*}{$\begin{array}{l}\text { Which vaccinations do you } \\
\text { recommend for your adult patients? }\end{array}$} & hepatitis B & 0 & 0.0 \\
\hline & influenza & 552 & 73.4 \\
\hline & meningococcal & 0 & 0.0 \\
\hline & Pneumococcal & 57 & 7.6 \\
\hline & Tetanus & 127 & 16.9 \\
\hline & Other vaccines & 16 & 2.1 \\
\hline \multirow[t]{4}{*}{$\begin{array}{l}\text { If your adult patients do not recommend } \\
\text { vaccination, what is the reason? }\end{array}$} & $\begin{array}{c}\text { Do not believe in the efficacy of } \\
\text { vaccinations }\end{array}$ & 8 & 7.5 \\
\hline & Pay for vaccinations & 29 & 27.1 \\
\hline & I cannot find time due to my busy work & 61 & 57.0 \\
\hline & other & 9 & 8.4 \\
\hline \multirow[t]{2}{*}{ Are you getting yourself vaccinated? } & Yes & 678 & 85.4 \\
\hline & No & 116 & 14.6 \\
\hline \multirow{4}{*}{$\begin{array}{c}\text { If you got yourself a vaccine, } \\
\text { which vaccinations did you make? }\end{array}$} & Hepatitis B & 59 & 8.5 \\
\hline & İnfluenza & 309 & 44.5 \\
\hline & Tetanus & 313 & 45.0 \\
\hline & other & 14 & 2.0 \\
\hline \multirow[t]{4}{*}{ If you do not, what is the reason? } & $\begin{array}{l}\text { Not believing in the efficacy of } \\
\text { vaccination }\end{array}$ & 18 & 17.1 \\
\hline & Unnecessary sight & 4 & 3.8 \\
\hline & I cannot find time due to my busy work & 60 & 57.1 \\
\hline & Other & 23 & 21.9 \\
\hline
\end{tabular}


the 25 - 34 age group, people who have previously been trained in vaccination and people who follow guidelines for vaccination has higher rates of vaccination.

The comparison between the socio-demographic characteristics of health workers and vaccination status is given in Table 7 .

Table 7. The relationship of the socio-demographic characteristics of health workers and vaccination status.

\begin{tabular}{|c|c|c|c|c|c|c|}
\hline & & \multicolumn{4}{|c|}{ Are you getting vaccination yourself? } & \multirow[b]{3}{*}{$\mathrm{P}$} \\
\hline & & \multicolumn{2}{|c|}{ Yes } & \multicolumn{2}{|c|}{ No } & \\
\hline & & $\mathrm{n}$ & $\%$ & $\mathrm{n}$ & $\%$ & \\
\hline \multirow[t]{2}{*}{ Gender } & Male & 110 & 16.2 & 29 & 25.0 & $0.022^{*}$ \\
\hline & Female & 568 & 83.8 & 87 & 75.0 & \\
\hline \multirow[t]{4}{*}{ Age group } & $18-24$ & 31 & 4.6 & 8 & 6.9 & $0.048^{*}$ \\
\hline & $25-34$ & 272 & 40.3 & 36 & 31.0 & \\
\hline & $35-44$ & 259 & 38.4 & 42 & 36.2 & \\
\hline & 45 and upper & 113 & 16.7 & 30 & 25.9 & \\
\hline \multirow[t]{4}{*}{ Duration of vocation } & $0-9$ & 243 & 37.6 & 42 & 37.8 & 0.976 \\
\hline & $10-19$ & 224 & 34.6 & 38 & 34.2 & \\
\hline & $20-29$ & 164 & 25.3 & 29 & 26.1 & \\
\hline & 30 and upper & 16 & 2.5 & 2 & 1.8 & \\
\hline \multirow[t]{5}{*}{ Marital status } & Living separate & 5 & 0.7 & 0 & 0.0 & 0.714 \\
\hline & Single & 138 & 20.4 & 26 & 22.4 & \\
\hline & Divorced & 38 & 5.6 & 6 & 5.2 & \\
\hline & Widow & 6 & 0.9 & 0 & 0.0 & \\
\hline & Married & 491 & 72.4 & 84 & 72.4 & \\
\hline \multirow[t]{2}{*}{ Place of vocation } & Rural & 547 & 80.7 & 87 & 75.0 & 0.159 \\
\hline & Urban & 131 & 19.3 & 29 & 25.0 & \\
\hline \multirow[t]{4}{*}{ Occupation } & Family medicine & 264 & 39.5 & 57 & 50.0 & 0.208 \\
\hline & Other specialist & 31 & 4.6 & 5 & 4.4 & \\
\hline & Midwife-nurse & 360 & 53.8 & 50 & 43.9 & \\
\hline & $\begin{array}{l}\text { Other health care } \\
\text { worker }\end{array}$ & 14 & 2.1 & 2 & 1.8 & \\
\hline \multirow{2}{*}{$\begin{array}{l}\text { Have you ever been } \\
\text { trained in adult } \\
\text { vaccination before? }\end{array}$} & Yes & 341 & 50.3 & 39 & 33.6 & $0.001^{*}$ \\
\hline & No & 337 & 49.7 & 77 & 66.4 & \\
\hline \multirow{2}{*}{$\begin{array}{l}\text { Do you follow the } \\
\text { guidelines on } \\
\text { vaccination? }\end{array}$} & Yes & 562 & 82.9 & 81 & 69.8 & $0.001^{*}$ \\
\hline & No & 116 & 17.1 & 35 & 30.2 & \\
\hline \multirow{4}{*}{$\begin{array}{c}\text { If yes to the previous } \\
\text { question, where did } \\
\text { you get this } \\
\text { information? }\end{array}$} & $\begin{array}{c}\text { From vaccination } \\
\text { guidelines }\end{array}$ & 230 & 72.3 & 23 & 65.7 & 0.829 \\
\hline & From educations & 63 & 19.8 & 9 & 25.7 & \\
\hline & $\begin{array}{l}\text { From social } \\
\text { platforms }\end{array}$ & 14 & 4.4 & 2 & 5.7 & \\
\hline & other & 11 & 3.5 & 1 & 2.9 & \\
\hline
\end{tabular}

Kikare test; Exact test; Frequency distributions of a: $0.05^{*}$ groups were statistically significant. 


\section{Discussion}

In the literature, adult vaccination has generally been considered in terms of patients or health care workers. Our study is different from others because it is a study that deals both together. In addition, in the literature mostly influenza vaccination has been conducted and adult vaccinations have not been evaluated in general. Our study evaluates all adult vaccines.

In our study, adult vaccination rate is $60 \%$. When we examine other studies conducted in our country, it is seen that this ratio changed between $30.4 \%$ and $41 \%$, but most of these studies were done in individuals over 65 years old. The target group of our study is adult individuals over 18 years of age, and when we are grouped by age, our vaccination results in our group over 50 years are much more pleasant. Compared with these results, it is possible to say that the rate of vaccination in our study is high. But the patients who do not have regular vaccination and who only get once vaccination were included in our results. This can be attributed to the increasing recognition of the importance of the condition of the patients over the years and to the further recommendation of adult vaccination by primary caregivers [8] [9] [10].

When the vaccine distributions of the vaccinated recipients were examined, it was found that most of them had an influenza vaccine [68.1\%]. This rate is higher than the other studies done in the primary care in our country, but it is low in a family medicine outpatient clinic of an education research hospital in Istanbul. Influenza outbreaks that have recently been seen at different times, and the awareness of influenza in these individuals, especially in those who have frequent involvement in the media, and the free provision of vaccine may have contributed to this [8] [9] [10].

The influenza vaccination rates in the World are 51.4\% in Germany; $19.5 \%$ in Poland; 44.8\% in America; 25.1\% in Spain and those rates are lower than our country. However, there are differences in the studies carried out and in some studies seasonal influenza vaccination has been questioned [11] [12] [13] [14]. In our work, such a separation has not been done.

Although the influenza vaccination rates in our study are good, it is not possible to say the same for other vaccines. Our pneumococcal immunization rates are significantly lower than other studies in the world [3.9\%]. While these rates are between $11.5 \%$ and $56 \%$ in the world while they are in the range of $3.4 \%$ $10 \%$ in our country, our results are similar to the studies done in our country but far behind the world countries. In another study conducted in Canada with adults aged 65 years and over, pneumococcal vaccination rates were found to be $49.8 \%$. $43.4 \%$ of the vaccinated people are in the 75 - 84 age group [8] [9] [13] [14] [15] [16].

Another poor outcome in terms of vaccination rates in our study also occurred in tetanus vaccines. The rate of tetanus immunization in our study was $13.7 \%$ and far behind the rate of tetanus inoculation in both our country and the world. In Germany, tetanus immunization rates among participants were very 
high [95.4\%]. The tetanus vaccination campaigns made by the Ministry of Health in Turkey should be more effective [2] [6] [7]. The fact that the tetanus vaccine contained in the vaccines to be done in the adult population is not performed by patients in a large scale may be due to lack of knowledge of the patient and physician or ignoring the tetanus vaccine as much as the influenza vaccine.

There are many factors that influence vaccination rates. In our study, it was observed that the vaccination status was influenced by sociodemographic factors such as age, gender, education, occupation and chronic illness. Women, 50 and older age groups, primary school graduates, housewives and people with chronic illnesses were found to highly vaccinated in our study. Different from our study, the trial conducted in primary care of Poland there are statistically significance between marital status, occupation, presence of chronic illness, previous influenza vaccination, previously informed about the vaccination by physician and vaccination status.

Vaccination rates were found to be higher in married people, in retired, in chronic illness presenters, in those who were previously vaccinated, when the physician was informed about the vaccine, when the physician was informed about where the vaccine would be taken, and if the infection was considered dangerous for health and life.

In a study, unlike our study, only a significant relation was found between the level of education and the status of vaccination and it was observed that people with higher education levels were more vaccinated [17]. In a study conducted by Hamidi and colleagues in Istanbul, the attitude towards pneumococcal and tetanus vaccination and the need for tetanus vaccination was found to be significantly higher in the high income group [15].

However, in our study, no relation was established between income level and vaccination rates.

In our study we found that women and primary school graduates vaccined especially with pnömococcus and tetanus, all of the 50 and older age group vaccinated with pnömococcus, the biggest part of vaccinated people with pnömococcus and tetanus were house wives and the biggest part of vaccinated people with influenza were retired people, all of the pnomocooccus vaccinated people and the biggest part of influenza vaccinated people had chronic disease and all these results were statistically significant. These results are different from study of Mutlu and his friends.

In our study, there was a statistically significant difference between having knowledge about vaccination and level of education and profession $[p<0.05]$, different from Asık and his friends. No relationship between knowledge of vaccination and higher education level was found. It has been seen that most of those who say that having knowledge about the vaccine were primary school graduates. Housewives and retirees constitute a large part of those who have knowledge as a profession. This can be due to the fact that primary school gra- 
duates and housewives are using healthcare services much more and they have acquired the knowledge in this way [13].

According to our study, the most knowledgeable vaccine is influenza vaccine and is compatible with the work of Asik and his colleagues. In our study, knowledge of influenza, pneumomococcus and tetanus vaccination was $85.7 \% ; 0.4 \%$ and $1.6 \%$ respectively, whereas in the study of Hamidi et al. $90.3 \% ; 43.5 \%$ and $83 \%$ respectively [15]. The level of knowledge about the vaccines in our study is low than this study; this may be due to our study being done in the primary health care facility instead of the hospital.

In our study, patients were asked if they believed they were benefiting from adult vaccination, and $72 \%$ of the patients indicated that they believed benefited from the vaccine, however their immunization levels were below this rate.In our study, the benefits of vaccinations were not individually questioned, but were generally addressed.

The inability of individuals to access health services due to limited economic opportunities and the lack of knowledge related to health affect vaccination rates negatively [17] [18] [19].

$34.3 \%$ of the patients in our study group were not vaccinated due to lack of information and this result is consistent with the literature [8]. Among our reasons for not vaccinating in our study, the first reason to not vaccinating was not have knowledge about the vaccine, followed by afraid of vaccination and not believing in the efficacy of vaccination. In many studies, the most common reasons for not vaccinating are that there are no suggestions for vaccination and that they are not aware of the risks that may result from vaccination [20] [21] [22].

In a study, it has been stated that most of the patients in the target group to be vaccinated are not aware of influenza and pneumococcal vaccination [23] and these result is in agreement without study. Based on this, it can be said that how important it is for physicians and patients to be aware of patients about vaccinations.

One of the most important result of our study was that patients want to get information about vaccinations from primary care, which is the first point of contact. This shows that a great deal of work has been done to primary health care providers in informing about adult vaccinations. The second of the places where the participants want to be informed is the public spots, which shows us that the media has an important place in our lives and that the patients are more influenced by the information on the media.

Influenza vaccination rates among health care workers in Turkey is 8.8 to $28.5 \%$. In a study conducted in health workers in a hospital in Konya, the rate of health personnel who had influenza vaccination was $16.7 \%$, our study is much higher than those rates [44.5\%] [24]. Studies conducted at the primary care showed higher influenza vaccination rates [23]-[29]. The reasons of this may that; the primary care is the primarily responsible from vaccines, the primary care workers may be more sensitive to this issue or they see themselves at much 
more risk. In a similar study conducted in Poland with both patients and physicians and in our study, $82 \%$ of physicians were vaccinated for influenza. Most of the vaccinated physicians were physicians working in the family medicine unit [5]. In a study conducted by James et al. in Africa, very low rates of influenza vaccination [6.5\%] were found, which was largely due to low awareness of influenza [21]. In a study conducted in Australia, 70\% of influenza vaccination rates were found and that primary care stuff had more influenza vaccination than the healthcare staff in the hospitals [22]. Our work also supports this result.

In a study conducted in the United States with family physicians regarding pneumococcal vaccinations, pneumococcal immunization rates ranged from 37 to $47 \%$ in that area. In this study, vaccination rates of physicians who have been professed longer were found to be less vaccinated, in accordance with our study [25].

In a study conducted in Ege University, hepatitis vaccination rate was found $43.3 \%$, tetanus vaccination rate was found $32 \%$ [26]. Our rates were lower than Hepatitis $B$ rates, higher than tetanus rates. This may be due to the fact that health care workers working in tertiary care may see themselves at greater risk for Hepatitis B and tetanus.

In the study conducted by Mistık and his colleagues, $83 \%$ of physicians believe that adult vaccination is important and $90 \%$ believe that adults should be vaccinated, but only $9.2 \%$ of them recommend vaccination to their adult patients [23]. $31 \%$ of the physicians were not vaccinated. In our study recommendation and vaccination rates of physicians were higher.

\section{Conclusions}

As a result of the studies including our study about adult vaccination, only $10 \%$ $20 \%$ of the targeted groups in adults can be vaccinated. However, just like in childhood during adulthood, vaccinations protect individuals from diseases and provide economic benefits. However, the achievement of these successes depends on the plan, program, leadership, coordination and continuity in practice.

Due to the above reasons, immunization services for adults and elderly people should be provided. In order to provide these services, an immunization program covering not only childhood but all life spans is needed. This program can be called "Lifelong Immunization Program". In the framework of this program, it should recommend that immunization services that start in childhood should continue uninterruptedly in adult and old age. Immunization services to be carried out under this program can be maintained by being organized and monitored at the level of family medicine. Adequate immunization rates in adults and the elderly are not possible when vaccination is left to requesting of person. It is very important that family physicians, who are the primary preventive and curative physicians of adult health, should develop and update their knowledge about immunization and train these patients in the field.

Firstly, the knowledge level of physicians on adult immunization should be 
updated with in-service trainings, they should first be convinced to vaccinate because they are in risk group and then the $y$ should be recommended vaccination to patient to increase the vaccination rates.

If enough motivation is provided for adult vaccination in family physicians who have achieved great success by keeping vaccination rates at high levels in childhood vaccinations, it is obvious that the targets will also be achieved in adult immunization rates.

\section{Conflicts of Interest}

The authors declare no conflicts of interest regarding the publication of this paper.

\section{References}

[1] EKMUD (2016) Adult Immunization Guideline.

[2] Tosun, S., et al. (2017) Tetanus in Adults: Results of the Multicenter ID-IRI Study. European Journal of Clinical Microbiology \& Infectious Diseases, 36, 1455-1462. https://doi.org/10.1007/s10096-017-2954-3

[3] Advisory Committee on Immunization Practices, Centers for Disease Control, Prevention [CDC] (2013) Recommended Adult Immunization Schedule-United States. $M M W R, 2013,62$.

[4] Esposito, S., Durando, P., Bosis, S., Ansaldi, F., Tagliabue, C., Icardi, G. and ESCMID Vaccine Study Group [EVASG] (2014) Vaccine-Preventable Diseases: From Paediatric to Adult Targets. European Journal of Internal Medicine, 25, 203-212. https://doi.org/10.1016/j.ejim.2013.12.004

[5] Ezeh, A.C., Bongaarts, J. and Mberu, B. (2012) Global Population Trends and Policy Options. Lancet, 380, 142-148. https://doi.org/10.1016/S0140-6736(12)60696-5

[6] Orenstein, W.A. (2006) The Role of Measles Elimination in Development of a National Immunization Program. Pediatric Infectious Disease Journal, 25, 1093-101. https://doi.org/10.1097/01.inf.0000246840.13477.28

[7] Ünlüoğlu, İ. and Pala, B. (2011) Erişkinlerde aşılama. Turkiye Klinikleri Family Medicine-Special Topics, 2, 66-69.

[8] Bal, H. and Borekci, G. (2016) Investigation of the Adult Vaccination Status and Influencing Factors in People Aged 65 Years and Over Registered in a Family Health Center in Mersin City. Istanbul Medical Journal, 17, 121-301. https://doi.org/10.5152/imj.2016.69783

[9] Toledo, D., Soldevila, N., Guayta-Escolies, R., Lozano, P., Rius, P., Gascón, P. and Domínguez, A. (2017) Knowledge of and Attitudes to Influenza Vaccination among Community Pharmacists in Catalonia [Spain]. 2013-2014 Season: A Cross Sectional Study. International Journal of Environmental Research and Public Health, 14, pii: E756. https://doi.org/10.3390/ijerph14070756

[10] Nessler, K., Krztoń-Królewiecka, A., Chmielowiec, T., Jarczewska, D. and Windak, A. (2014) Determinants of Influenza Vaccination Coverage Rates among Primary Care Patients in Krakow, Poland and the Surrounding Region. Vaccine, 32, 7122-7127. https://doi.org/10.1016/j.vaccine.2014.10.026

[11] Williams, W.W., Lu, P.J., O'Halloran, A., Kim, D.K., Grohskopf, L.A., Pilishvili, T., et al. (2017) Surveillance of Vaccination Coverage among Adult Populations-United States, 2015. MMWR Surveillance Summaries, 66, 1-28. 
https://doi.org/10.15585/mmwr.ss6611a1

[12] Klett-Tammen, C.J., et al. (2016) Determinants of Tetanus, Pneumococcal and Influenza Vaccination in the Elderly: A Representative Cross-Sectional Study on Knowledge, Attitude and Practice [KAP]. BMC Public Health, 16, 121. https://doi.org/10.1186/s12889-016-2784-8

[13] Sabapathy, D., Strong, D., Robert, M., Li, B. and Quan, H. (2014) Pneumococcal Vaccination of the Elderly during Visits to Acute Careproviders: Who Are Vaccinated? Preventive Medicine, 62, 155-160. https://doi.org/10.1016/j.ypmed.2013.11.009

[14] Dyda, A., Karki, S., Hayen, A., MacIntyre, C.R., Menzies, R., Banks, E., Kaldor, J.M. and Liu, B. (2016) Influenza and Pneumococcal Vaccination in Australian Adults: A Systematic Review of Coverage and Factors Associated with Uptake. BMC Infectious Diseases, 16, 515. https://doi.org/10.1186/s12879-016-1820-8

[15] Ahmad Hamidi, A., Gelmez Taş, B., Gündüz, A., Nur Çelebi, S., Esen, E.S., Toprak, D. and Dökmetaş, İ. (2018) Immunization Rates of Pneumococcal, Influenza and Tetanus Vaccines and Knowledge and Attitudes of Adult Patients Who Receive Inpatient Treatment at Hospital: Point Prevalence Study. Human Vaccines \& Immunotherapeutics, 18, 1-5. https://doi.org/10.1080/21645515.2018.1489187

[16] Böhmer, M.M., Walter, D., Krause, G., Müters, S., Gösswald, A. and Wichmann, O. (2011) Determinants of Tetanus and Seasonal İnfluenza Vaccine Uptake in Adults Living in Germany. Human Vaccines, 7, 1317-1325. https://doi.org/10.4161/hv.7.12.18130

[17] Urun, Y., Akbulut, H., Demirkazik, A., Cay Senler, F., Utkan, G., Onur, H. and Icli, F. (2013) Perception about İnfluenza and Pneumococcal Vaccines and Vaccination Coverage among Patients with Malignancies and Their Family Members. Journal of $B U O N, 18,511-515$.

[18] Peter, H., Williams, A., Burgess, M.A. and Wang, H. (2005) Prevalence and Determinants of İnfluenza Vaccination in Australians Aged 40 Years and over a National Survey. Australian and New Zealand Journal of Public Health, 29, 35-37. https://doi.org/10.1111/j.1467-842X.2005.tb00745.x

[19] Santibanez, T.A., Nowalk, M.P., Zimmerman, R.K., et al. (2002) Knowledge and Beliefs about İnfluenza, Pneumococcal Disease, and İmmunizations among Older People. Journal of the American Geriatrics Society, 50, 1711-1716. https://doi.org/10.1046/j.1532-5415.2002.50466.x

[20] Baykan, Z., Naçar, M., Özdemir, S.B., Poyrazoğlu, S. and Çetinkaya, F. (2011) Knowledge and Attitude of Family Physicians Regarding Adult Vaccination. World Journal of Vaccines, 1, 92-97. https://doi.org/10.4236/wjv.2011.13009

[21] James, P.B., Rehman, I.U., Bah, A.J., Lahai, M., Cole, C.P. and Khan, T.M. (2017) An Assessment of Healthcare Professionals' Knowledge about and Attitude towards Influenza Vaccination in Freetown Sierra Leone: A Cross-Sectional Study. BMC Public Health, 17, 692.

[22] Ward, K., Seale, H., Zwar, N., Leask, J. and MacIntyre, J.R. (2011) Annual İnfluenza Vaccination: Coverage and Attitudes of Primary Care Staff in Australia. Influenza Other Respir Viruses, 5, 135-141. https://doi.org/10.1111/j.1750-2659.2010.00158.x

[23] Mistik, S., Balci, E. and Elmali, F. (2012) Primary Healthcare Professionals' Knowledge, Attitude and Behavior Regarding İnfluenza İmmunization: 2006-2007 Season Adverse Effect Profile. Bratislavske Lekarske Listy, 113, 384-388. https://doi.org/10.4149/BLL_2012_088

[24] Cihan, F.G., Durmaz, F.G., Odabas, D., Baydemir, C. and Fatma, K. (2012) 
Attitudes toward and Factors Affecting Influenza Vaccination among Physicians and Nurses of a Tertiary-Care Hospital in the Central Anatolia Region of Turkey. Postgraduate Medicine, 124, 117-123. https://doi.org/10.3810/pgm.2012.11.2602

[25] Noe, C.A. and Markson, L.J. (1998) Pneumococcal Vaccination: Perceptions of Primary Care Physicians. Postgraduate Medicine, 27, 767-772.

https://doi.org/10.1006/pmed.1998.0393

[26] Türkistanll, E., Şenuzun, Fe., Karaca, Bs., San, A. and Aydemir, G. (2000) The State of the Immunization of the Health Workers Who Have Workıng in Ege University Research Hospital. Ege Tip Dergisi, 39, 29-32.

[27] Ortiz, M.A., Abd, K.M., Caballero, J.M. and Allam, M.F. (2011) Coverage and Side Effects of İnfluenza A [H1N1] 2009 Monovalent Vaccine among Primary Health Care Workers. Vaccine, 29, 6366-6368.

https://doi.org/10.1016/j.vaccine.2011.04.117

[28] Kraut, A., Graff, L. and McLean, D. (2011) Behavioral Change with İnfluenza Vaccination: Factors İnfluencing İncreased Uptake of the Pandemic H1N1 versus Seasonal İnfluenza Vaccine in Health Care Personnel. Vaccine, 29, 8357-8363. https://doi.org/10.1016/j.vaccine.2011.08.084

[29] Abramson, Z.H. and Levi, O. (2008) Influenza Vaccination among Primary Healthcare Workers. Vaccine, 26, 2482-2489.

https://doi.org/10.1016/j.vaccine.2008.03.011 